\title{
New cholinesterase inhibitors for Alzheimer's disease: Structure Activity Studies (SARs) and molecular docking of isoquinolone and azepanone derivatives
}

\author{
Patrícia Bacalhau ${ }^{b, d}$, Amor A. San Juan ${ }^{c}$, Carolina S. Marques ${ }^{c}$, Daniela Peixoto ${ }^{c}$, Albertino Goth $^{c}$, \\ Cátia Guarda ${ }^{\mathrm{d}}$, Mara Silva ${ }^{\mathrm{d}}$, Sílvia Arantes ${ }^{\mathrm{b}, \mathrm{d}}$, A. Teresa Caldeira ${ }^{\mathrm{a}, \mathrm{d}}$, Rosário Martins ${ }^{\mathrm{a}, \mathrm{b}, \mathrm{d}}$, \\ Anthony J. Burke ${ }^{\mathrm{a}, \mathrm{c}, *}$ \\ a Departamento de Química, Escola de Ciências e Tecnologia, Universidade de Évora, Rua Romão Ramalho 59, 7000-671 Évora, Portugal \\ b ICAAM-Instituto de Ciências Agrárias e Ambientais Mediterrânicas, Institute for Research and Advanced Studies (IIFA), Universidade de Évora, Ap. 94, 7002-554 Évora, Portugal \\ ' Centro de Química de Évora, Institute for Research and Advanced Studies (IIFA), Universidade de Évora, Rua Romão Ramalho, 59, 7000 Évora, Portugal \\ ${ }^{\mathrm{d}}$ Laboratório HERCULES, Institute for Research and Advanced Studies (IIFA), Universidade de Évora, Palácio do Vimioso, Largo Marquês de Marialva, 8, 7000-809 Évora, Portugal
}

\section{A R T I C L E I N F O}

\section{Article history:}

Received 26 January 2016

Revised 28 April 2016

Accepted 13 May 2016

Available online 14 May 2016

\begin{abstract}
A B S T R A C T
A library of isoquinolinone and azepanone derivatives were screened for both acetylcholinesterase (AChE) and butyrylcholinesterase (BuChE) activity. The strategy adopted included (a) in vitro biological assays, against eel AChE (EeAChE) and equine serum BuChE (EqBuChE) in order to determine the compounds $\mathrm{IC}_{50}$ and their dose-response activity, consolidated by (b) molecular docking studies to evaluate the docking poses and interatomic interactions in the case of the hit compounds, validated by STD-NMR studies. Compound (1f) was identified as one of these hits with an $\mathrm{IC}_{50}$ of $89.5 \mu \mathrm{M}$ for EeAChE and $153.8 \mu \mathrm{M}$ for EqBuChE, (2a) was identified as a second hit with an $\mathrm{IC}_{50}$ of $108.4 \mu \mathrm{M}$ (EeAChE) and $277.8 \mu \mathrm{M}(\mathrm{EqBuChE})$. In order to gain insights into the binding mode and principle active site interactions of these molecules, $(R)-(\mathbf{1 f})$ along with 3 other analogues (also as the $R$-enantiomer) were docked into both RhAChE and $h \mathrm{BuChE}$ models. Galantamine was used as the benchmark. The docking study was validated by performing an STD-NMR study of (1f) with EeAChE using galantamine as the benchmark.
\end{abstract}

(c) 2016 Elsevier Inc. All rights reserved.

\section{Introduction}

Life style improvement as well as better health care, coupled with significant advances in medical technologies in the last century, has permitted an increase in average life expectancy, however the downside is the increased incidence of dementia in the global population. In 2010, estimates pointed to 35.6 million people with dementia worldwide, a number that is expected to double every 20 years, reaching 115.4 million cases in 2050, 60-70\% of which have been assigned to Alzheimer's disease (AD) [1]. This is the most common form of dementia and causes a progressive and irreversible neurodegeneration. AD is related with loss of cholinergic function, which affects memory, learning and behavior [2]. A large part of the strategies for treating $\mathrm{AD}$ have been based on the cholinergic hypothesis, which postulates that memory loss in Alzheimer's patients is associated with a deficit of cholinergic function

* Corresponding author at: Departamento de Química, Escola de Ciências e Tecnologia, Universidade de Évora, Rua Romão Ramalho 59, 7000-671 Évora, Portugal.

E-mail address: ajb@uevera.pt (A.J. Burke). in the brain [3,4]. The loss of cholinergic neurons leads to the progressive reduction of acetylcholine $(\mathrm{ACh})$ in the brain and resulting cognitive impairment in $\mathrm{AD}$ [5]. As such, the enzyme acetylcholinesterase (AChE) has been one of the prime targets in the search for a treatment for $A D$, which uses reversible inhibitors of $\mathrm{AChE}$, in order to increase levels of $\mathrm{ACh}$ in the brain [6,7]. ACh is hydrolyzed by both $\mathrm{AChE}$ and butyrylcholinesterase (BuChE). Although little is known about the physiological role of BuChE $[8,9]$, particularly in the central nervous system, studies have been made in order to determine its influence on the treatment of $A D$ $[10,11]$. It was found that in the course of the disease, levels of AChE in the CNS decrease contrary to what happens with BuChE [12]. Both enzymes represent legitimate therapeutic targets for ameliorating the cholinergic deficit characteristic of AD.

Considering their broad biological activity spectrum, the isoquinolinone scaffold is a privileged-scaffold lead for targeting various diseases and these compounds were chosen for this study [13]. Isoquinolines are alkaloids found in several bioactive natural products [14-17]. They are biogenetically derived from phenylalanine [18], and exhibit antidepressant [19], anti-inflammatory [20] and analgesic $[21,22]$ characteristics. For this reason this family 
was chosen for evaluating their ChE inhibitory properties. The azepanone family was chosen on the basis of their analogy with galantamine which contains an azepane ring, and it is the azepane ring which is recognized as the important pharmacophore element for ChE inhibition (see below).

The objective of the present study was to evaluate the inhibitory capacity of a series of isoquinolinone and azepanone derivatives for AChE and BuChE targets. The biological assays involved a modified in vitro Ellman method [6,23]. Furthermore, by comparing the $\mathrm{IC}_{50}$ values and $\mathrm{AChE}$ selectivity index ( $\mathrm{SI}, \mathrm{IC}_{50} \mathrm{BuChE} / \mathrm{IC}_{50}$ AChE) and by analyzing the inhibitor-enzyme interaction using docking studies combined with STD-NMR validation studies, we obtained important insights on the nature of the interaction of these molecules with the enzyme active site, making the design of better ChE inhibitors (ChEIs) possible.

\section{Results and discussion}

\subsection{Chemical synthesis}

In an earlier report by our group [24], an innovative transitionmetal-catalysed intramolecular cyclization reaction of amido(hetero)arylboronic acid aldehydes to isoquinolin-1(2H)-one derivatives was developed. Starting from easily accessed acetal substrates, an efficient three-step synthetic approach was reported
[24] (Scheme 1). A library of 16 isoquinolinone and azepanone derivatives (Schemes 1 and 2) were tested for cholinesterase inhibition.

The isoquinolinone derivative (1f) was obtained in $28 \%$ yield, from the iodide-acetal derivative in the first synthetic step, at $100{ }^{\circ} \mathrm{C}$ (see Scheme 2). This approach failed using the other acetal derivatives, however we decided to test compound (1f) to evaluate the importance of the 4-hydroxyl group on the ChE inhibition, as (1f) contains a 4-methoxyl substituent. We are currently investigating the mechanism of formation of this interesting compound, so that we can improve the synthetic method and enlarge the reaction scope.

\subsection{In vitro inhibition studies for $A C h E$ and $B u C h E$}

The biological assays to determine the compound $\mathrm{IC}_{50}$ followed a method based on the in vitro Ellman reaction [13,23,25]. We used Electrophorus electricus (eel) AChE (EeAChE) and equine serum BuChE (EqBuChE) as they are readily commercially available. The results of these inhibition studies are shown in Table 1 . The dose-response curves of both EeAChE and EqBuChE are presented in Fig. 1. In the case of $\mathrm{AChE}$, compound (1f) provided the best inhibition value (Table 1 , entry 6 ), showing the importance of the methoxyl group in position-4 (compare entries 1 and 6 , Table 1). The presence of electron withdrawing and weakly

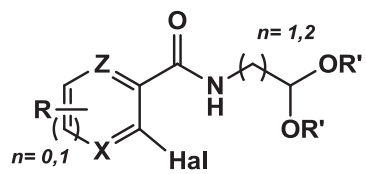

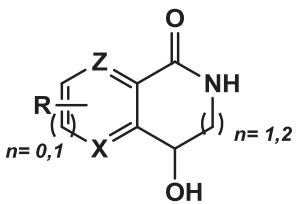

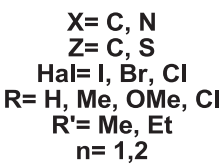<smiles>O=C1NCC(O)c2ccccc21</smiles>

(1a)<smiles>Cc1ccc2c(c1)C(=O)NCC2O</smiles>

(1b)<smiles>Cc1ccc2c(c1)C(O)CNC2=O</smiles>

(1c)<smiles>O=C1NCC(O)c2cc(Cl)ccc21</smiles>

(1d)<smiles>COc1ccc2c(c1)C(=O)NCC2O</smiles>

(1e) $\mathrm{OH}$<smiles>O=C1NCCC(O)c2ccccc21</smiles><smiles>Cc1ccc2c(c1)C(=O)NCCC2O</smiles>

(2b)<smiles>O=C1NCC(O)c2ncccc21</smiles>

(3a)<smiles>Cc1ccc2c(n1)C(O)CNC2=O</smiles>

(3b)<smiles>Cc1ccc2c(c1)C(O)CCNC2=O</smiles><smiles>COc1ccc2c(c1)C(=O)NCCC2O</smiles>

(2d) HO<smiles>O=C1NCCC(O)c2ncccc21</smiles>

(4a)<smiles>Cc1ccc2c(n1)C(O)CCNC2=O</smiles>

(4b)<smiles>O=C1NCC(O)c2ccsc21</smiles>

(5)<smiles>O=C1NCCC(O)c2ccsc21</smiles>

(6)

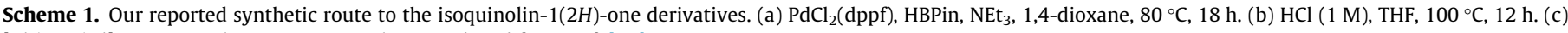
$[\mathrm{Rh}(\mathrm{COD}) \mathrm{Cl}]_{2}, \mathrm{~K}_{2} \mathrm{CO}_{3}$, Toluene, $100^{\circ} \mathrm{C}, 24 \mathrm{~h}$. Reproduced from Ref. [24]. 


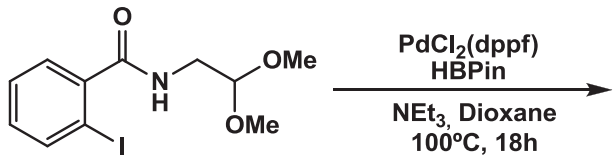

$t_{3, \text { Dioxane }}$<smiles>COC(CNC(=O)c1ccccc1B1OC(C)(C)C(C)(C)O1)OC</smiles><smiles>COC1CNC(=O)c2ccccc21</smiles>

Scheme 2. Synthetic route of isoquinolin-1(2H)-one (1f) (previously not reported).

Table 1

Inhibition studies for $\mathrm{AChE}$ and BuChE.

\begin{tabular}{cllll}
\hline Entry & Compound & $\begin{array}{l}\mathrm{IC}_{50} \text { EeAChE } \\
(\mu \mathrm{M})^{\mathrm{a}}\end{array}$ & $\begin{array}{l}\mathrm{IC}_{50} \\
E q \mathrm{BuChE} \\
(\mu \mathrm{M})^{\mathrm{a}}\end{array}$ & $\begin{array}{l}\text { Selectivity index } \\
\left(\mathrm{IC}_{50} \text { EeBuChE/IC } 50\right. \\
E q A C h E)\end{array}$ \\
\hline 1 & $\mathbf{1 a}$ & $136.0 \pm 8.8$ & $807.5 \pm 1.9$ & 5.938 \\
2 & $\mathbf{1 b}$ & $>1500$ & $352.1 \pm 17.7$ & N.D. \\
3 & $\mathbf{1 c}$ & $>1500$ & $>1500$ & N.D. \\
4 & $\mathbf{1 d}$ & $>1500$ & $226.1 \pm 20.8$ & N.D. \\
5 & $\mathbf{1 e}$ & $311.3 \pm 2.3$ & $>1500$ & N.D. \\
6 & $\mathbf{1 f}$ & $89.5 \pm 2.0$ & $153.8 \pm 2.6$ & 1.718 \\
7 & $\mathbf{2 a}$ & $108.4 \pm 3.4$ & $277.8 \pm 7.7$ & 2.563 \\
8 & $\mathbf{2 b}$ & $536.3 \pm 37.7$ & $108.0 \pm 8.1$ & 0.201 \\
9 & $\mathbf{2 c}$ & $564.4 \pm 21.8$ & $269.4 \pm 6.5$ & 0.477 \\
10 & $\mathbf{2 d}$ & $585.1 \pm 23.6$ & $108.6 \pm 15.7$ & 0.186 \\
11 & $\mathbf{3 a}$ & $1296.7 \pm 22.8$ & $>1500$ & N.D. \\
12 & 3b & $1251.7 \pm 180.9$ & $>1500$ & N.D. \\
13 & 4a & $550.4 \pm 17.8$ & $>1500$ & N.D. \\
14 & $\mathbf{4 b}$ & $>1500$ & $>1500$ & N.D. \\
15 & $\mathbf{5}$ & $1366.2 \pm 48.9$ & $>1500$ & N.D. \\
16 & $\mathbf{6}$ & $756.4 \pm 24.4$ & $825.6 \pm 16.1$ & 1.091 \\
17 & Galantamine & $3.5 \pm 0.5$ & $61.9 \pm 5.2$ & 0.05 \\
\hline
\end{tabular}

N.D. - Not detected at the concentrations tested.

${ }^{a} \mathrm{IC}_{50}$ values are expressed as mean $\pm \mathrm{SD}(\mathrm{n}=3)$ based on dose-response curves, using the Origin 8.0 Pro. electron-donating substituents in the aryl ring of isoquinolin-1 $(2 \mathrm{H})$-ones derivatives was found to affect the $\mathrm{IC}_{50}$ value considerably (see for instance entries $2-4$, Table 1 ) since they give very weak activities. In the case of compound (1e) - bearing the stronger methoxyl electron-donating group in the 8-position, a better $\mathrm{IC}_{50}$ of $311.3 \mu \mathrm{M}$ (Table 1 , entry 5) was obtained, this may have been due to stronger electron donation or perhaps due to effective binding of the methoxyl group in the enzyme active site. Comparing the azepanone compounds with their isoquinolinone counterparts it was noticed that (2b)-(2d) (with the isoquinolinone unit) were shown to be at least three times more potent than (1b)(1d) (with the azepanone unit) (Table 1, compare entries 7-9 with 2-4). (2a) was the exception in that it had a similar value to compound (1a) (Table 1, entries 1 and 7). However, in the case of both the azepanone and the isoquinolinone families, it was observed that aromatic substitution was deleterious for activity. Azepin-1 $(2 \mathrm{H})$-ones with pyridyl cores, regardless of having electron donor groups in the aryl ring or not gave similar $\mathrm{IC}_{50}$ values for EeAChE, compound (4a) $\left(\mathrm{IC}_{50}\right.$ of $\left.550 \mu \mathrm{M}\right)$ was the best candidate (Table 1 , compare entries 11-14). In the context of AChE inhibition, there was a big difference observed in the two molecules containing a thiophene core, for instance, isoquinolin-1(2H)-one (5) had an
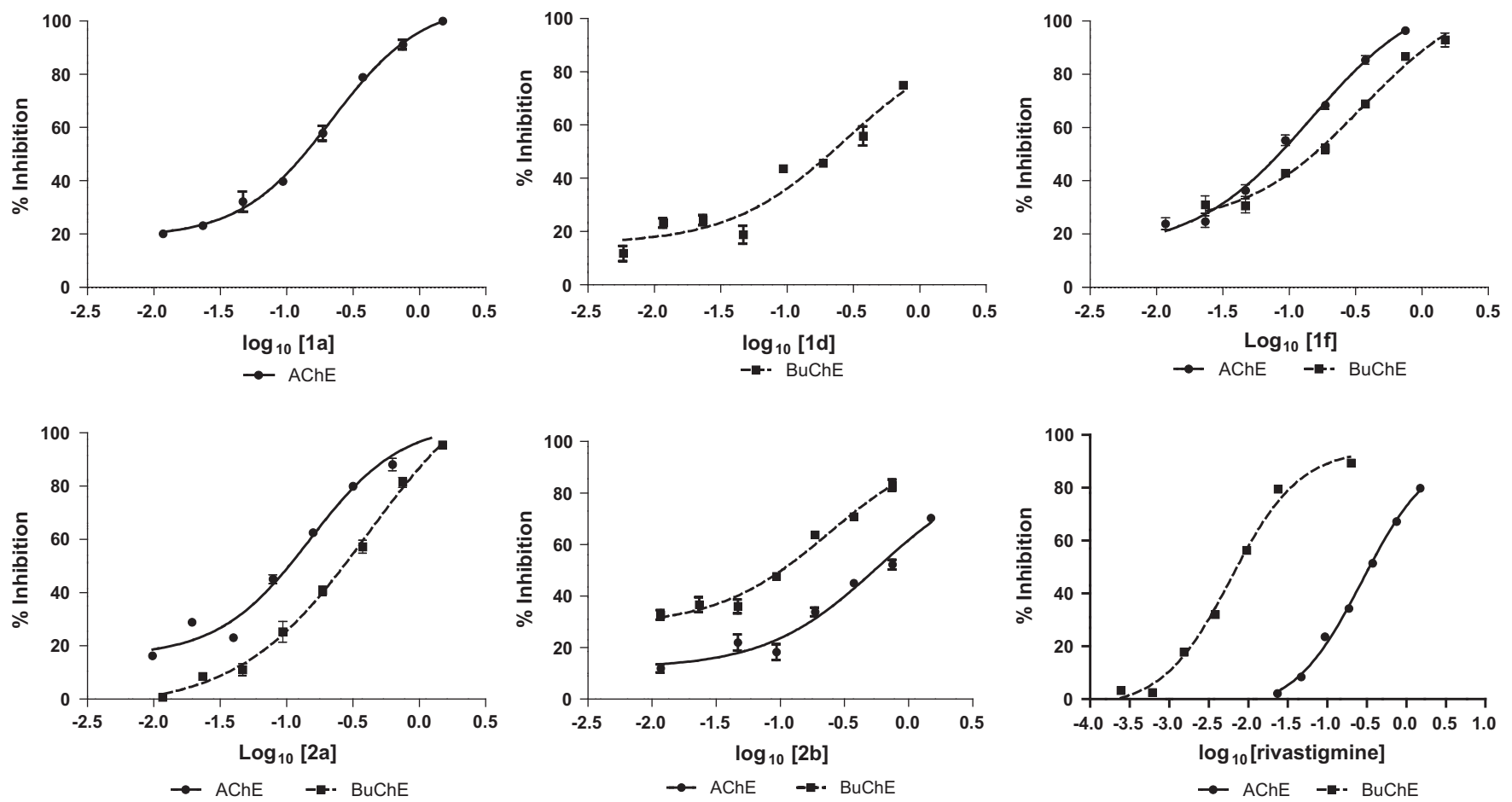

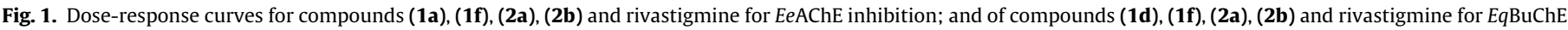
inhibition. (Rivastigmine which is a dual ChE inhibitor was used as the benchmark). 
$\mathrm{IC}_{50}$ almost twice that of azepin-1(2H)-one (6) (Table 1 , entries 15 and 16 , respectively). When compared to the galantamine benchmark, all our compounds showed higher $\mathrm{IC}_{50}$ values for both ChEs. Galantamine is a specific AChE inhibitor (see below for further discussion), but was used in this study with both enzymes.

In the case of BuChE, the azepin-1(2H)-one compounds gave better results than their isoquinolin-1(2H)-one counter-parts, independently of the type of substituent in the aryl ring. Compounds (2b) and (2d) gave the best $\mathrm{IC}_{50}$ values, which were $108.0 \mu \mathrm{M}$ and $108.6 \mu \mathrm{M}$, respectively (Table 1 , entries 8 and 10). Good IC $_{50}$ values were also obtained for the isoquinolin-1(2H)ones, as compound (1f) (Table 1 , entry 6 ) gave an $\mathrm{IC}_{50}$ value of $153.8 \mu \mathrm{M}$, which is the best result for these compounds with this enzyme. Moreover, the pyridyl and thiophene containing derivatives, regardless of the ring size, did not present any major differences in their $\mathrm{IC}_{50}$ values (Table 1 , entries 11-15), and displayed poor inhibition. Unfortunately, all these compounds were less active with EqBuAChE than the benchmark (all presented higher $\mathrm{IC}_{50}$ values). Compound (2b) gave the lowest value of $108.0 \mu \mathrm{M}$.

As can be seen from Table 1 , and the selectivity indexes, the isoquinolin-1(2H)-ones and azepin-1(2H)-ones with no substituents in the aryl ring, and the isoquinolinones and azepin-1 $(2 \mathrm{H})$-ones with pyridyl and thiophene units were selective for AChE, whilst isoquinolin-1(2H)-ones and azepin-1(2H)-ones with substituents in the aryl ring were selective for AChE.

Analysis of the dose-response curves (Fig. 1) revealed some interesting insights. Both compounds (1f) and (2a) showed similar behavior for EeAChE and EqBuChE inhibition (Fig. 1), this along with the respective $\mathrm{IC}_{50}$ values (Table 1 ), makes these compounds potential target inhibitors for both enzymes, and a structural basis for lead development design. Compound (1a) presented a doseresponse curve compatible with its corresponding $\mathrm{IC}_{50}$ value and shows potential to be a target drug for AChE (Fig. 1). Compounds (1e), (3a), (3b), (4a), (4b), (5) and (6) act as EeAChE activators at concentrations lower than 120.2, 426.6, 346.7, 331.1, 446.7, 363.1 and $190.5 \mu \mathrm{M}$, respectively (Fig. $S_{1}$, supplementary information). For higher concentrations they act as inhibitors. It is not yet clear why these compounds show this behavior. The same is true for the EqBuChE inhibitors (2d) and (3b) that act as activators for concentrations lower than 61.7 and $93.8 \mu \mathrm{M}$, respectively. For concentrations above $61.7 \mu \mathrm{M}$, compound (2d) shows good inhibition of EqBuChE (Fig. $\mathrm{S}_{1}$ ). In the case of compound (1d), for EqBuChE it presented an $\mathrm{IC}_{50}$ of $226.1 \mu \mathrm{M}$, but at half this concentration it presented a significant $40 \%$ inhibition and at a quarter the $\mathrm{IC}_{50}$ concentration, 30\% inhibition (Fig. 1). Compound (2c) presented an $\mathrm{IC}_{50}$ of $564.4 \mu \mathrm{M}$ for EeAChE, but at a concentration 2.5 times lower it gave a significant $30 \%$ inhibition. The same behavior was observed for compound (2d) in the case of EeAChE inhibition (Fig. $\mathrm{S}_{1}$ ).

Although compounds (3b), (5) and (6) were found to be poor inhibitors of EeAChE and EqBuChE we can see from Fig. $S_{1}$ that their dose response curves overlap at a concentration of $912.0 \mu \mathrm{M}(40 \%$ inhibition), $1000.0 \mu \mathrm{M}$ (40\% inhibition) and $512.9 \mu \mathrm{M}$ (30\% inhibition), respectively.

\subsection{Binding mode characterization using docking studies}

Critical to structure-based drug discovery is computational docking, which explores the position of small molecules within the binding site of the target biomacromolecule [26,27]. Cholinesterases are among the most efficient enzymes known. EeAChE (which we used in our bioactivity screening studies) possesses the three amino acids of the catalytic triad S203, E334 and H447, the aromatic residues F295 and F297, which define an acetylcholinespecific acyl pocket, the tryptophan residue W86, which interacts with the choline moiety in the active site, G121 and G122 - which

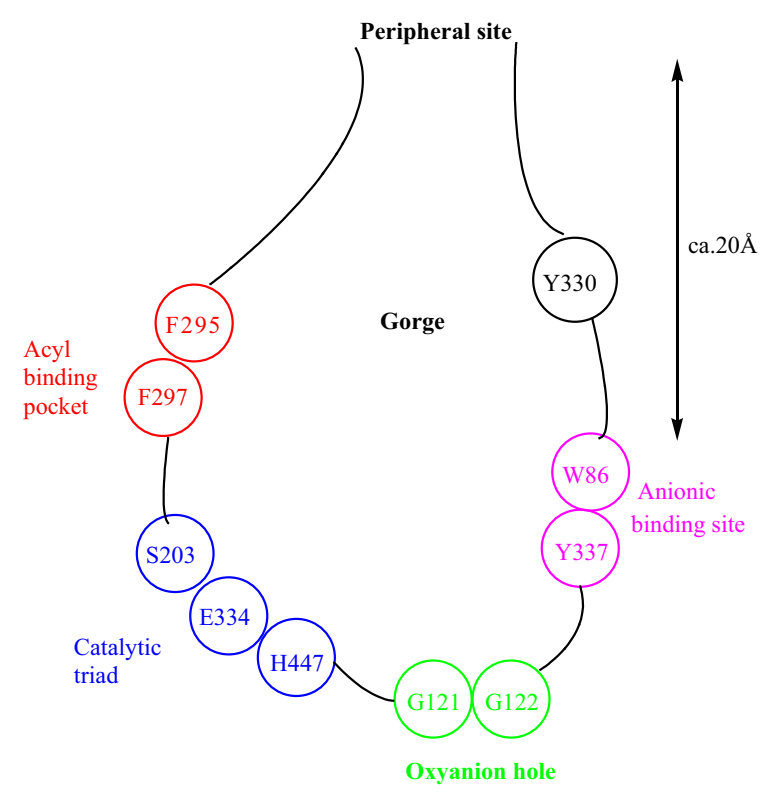

Fig. 2. Schematic representation of the active site gorge of EeAChE based on that of TcAChE [28b].

on the basis of structural analogy with TcAChE (see below in Fig. 2) would be part of the oxyanion hole - as well as the 14 aromatic residues lining the walls of a deep narrow gorge of about $20 \AA$ (Fig. 2) [28]. All 14 amino acids in the aromatic gorge are highly conserved across different species [28b]. Together with W86, Y337 constitutes the choline-binding subsite of the catalytic site [29]. Unfortunately, little structural information is available for EeAChE in contrast to Torpedo californica (ray) AChE (TcAChE) whose structure has been studied extensively, and we use as the basis of our model for EeAChE depicted in Fig. 2 [28b]. Thirteen of the gorge amino acid residues in EeAChE are identical to TcAChE, but Y330 of EeAChE is replaced by F330 in TcAChE [28]. The X-ray crystallographic analysis of TcAChE showed that it consists of a catalytic triad (S200-H440-E327) which lies close to the bottom of the deep and narrow gorge, which is lined with 14 aromatic amino acid residues [30a-30c]. Despite the complexity of this array of aromatic rings, it was suggested, on the basis of modelling with the active site of TcAChE - which involved docking of the acetylcholine (ACh) molecule in an all-trans configuration, that the quaternary group of the choline moiety makes close contact with the indole ring of W84 [28b,30b].

Human BuChE (hBuChE) and human AChE (hAChE) share 65\% amino acid sequence homology [31]. The crystal structure of ( $h \mathrm{BuChE}$ ) has already been solved [31b,31c]. This enzyme can hydrolyze toxic esters such as cocaine and scavenge organophosphorous pesticides and nerve agents [31b]. It is characterized by possessing the catalytic triad, S198, E325 and H438, the hydrophobic residues L286 and V288, which define the acyl pocket [31b]. The tryptophan amino acid residue $W 82$, interacts with the choline moiety in the catalytic active site via a $\pi$-cation interaction. The residues D70, Y332 and N83 constitute the peripheral anionic site (PAS) [13]. When compared, both TcAChE and $h \mathrm{BuChE}$ have the catalytic triad at the bottom of the gorge (20 A deep). In the case of TcAChE the gorge consists of aromatic residues and in the case of $E q B u C h E$ the gorge has hydrophobic residues. In contrast to $T c A C h E$, the EqBuChE acyl pocket has smaller, hydrophobic, amino acid residues, so it can accommodate bulkier inhibitors than in the case of AChE. In both enzymes the PAS is located at the outer rim of the gorge, and is an attraction center for substrates. The anionic site for both TcAChE and 
EqBuChE is found half-way down the gorge, between the peripheral and the acylation sites.

As we used EeAChE and EqBuChE for our bioassays and STD studies (see below), prior to conducting our molecular modelling studies we conducted sequence alignment studies, between, EeAChE and $h \mathrm{AChE}$, and between EqBuChE and $h \mathrm{BuChE}$ (Figs. $\mathrm{S}_{2}$ and $S_{3}$ ). What we saw was an overall identity of $88 \%$ and $90 \%$ for $\mathrm{AChE}$ and BuChE, respectively and no differences were detected for the amino acid sequences within the active sites between the human and non-human sources.

We analyzed and quantified the protein-ligand interactions by performing a computational docking that provides insight into molecular recognition for the cholinesterase inhibition assay. In our computational method, we used both recombinant human AChE (RhAChE) and human BuChE ( $h \mathrm{BuChE})$ crystal structures as input structures. We docked only the $(R)$-enantiomer in each case, even though the racemic mixture was used in the bioassays, on the basis that in the case of galantamine the stereogenic centre to which the $6-\mathrm{OH}$ group attached has the $(R)$-configuration, and this would appear to be a stereochemical requisite for favorable ligandenzyme interaction. The binding modes of $(R)-(\mathbf{1 f})$ and $(R)-(\mathbf{2 b})$, were expected to provide insights into their relatively good inhibition of both eeAChE and eqBuChE (see Figs. 2 and 3 ) and allow us to design a series of stronger binding lead compounds. Interestingly,
(R)-(1f) showed H-bonding (amide group) with the oxyanion pocket (G121, $2.92 \AA$, and G122, $3.04 \AA$ ), suggesting that it could inhibit AChE in a novel manner (unfortunately this could not be confirmed in our STD-NMR study - see below). Furthermore, the carbonyl oxygen of the amide formed a H-bond with S203 (2.60 ̊) whilst, the methoxyl oxygen formed a H-bond with Y124 (2.88 A). Remarkably, a $\pi-\pi$ stacking hydrophobic interaction formed between the aromatic ring of $(R)$-(1f) with the W86 residue at the anionic binding site of AChE, possibly stabilizing the ligandprotein complex (Fig. 3a). The structural modification of $(R)-(\mathbf{1 f})$ to $(R)-(\mathbf{1 e})$ - the latter having a methoxyl group in the aromatic ring, and a 4-OH group - showed a conformational change that favors a $\pi-\pi$ stacking interaction formed from the aromatic ring of $(R)-(\mathbf{1 e})$ with both W86 and F297 (Fig. $\mathrm{S}_{4}$ ). Furthermore, the amide nitrogen of $(R)-(\mathbf{1 e})$ formed a $\mathrm{H}$-bond with the carboxylic $\mathrm{OH}$ of E202. The interaction with the oxyanion pocket as was the case with (1f) was not evident for (1e), and this may explain its poorer binding affinity (see Table 1 ). To compare the binding mode of $(R)-(\mathbf{1 f})$ in the BuChE active site (Fig. 3 b), a favorable H-bond network was formed with the two conserved water molecules. We have shown previously that water molecules that are close to the binding site can lead to a conformational change that favors binding of the inhibitors [32]. These water molecules can be described as "sticky water" molecules and enhance the protein-ligand binding. Our
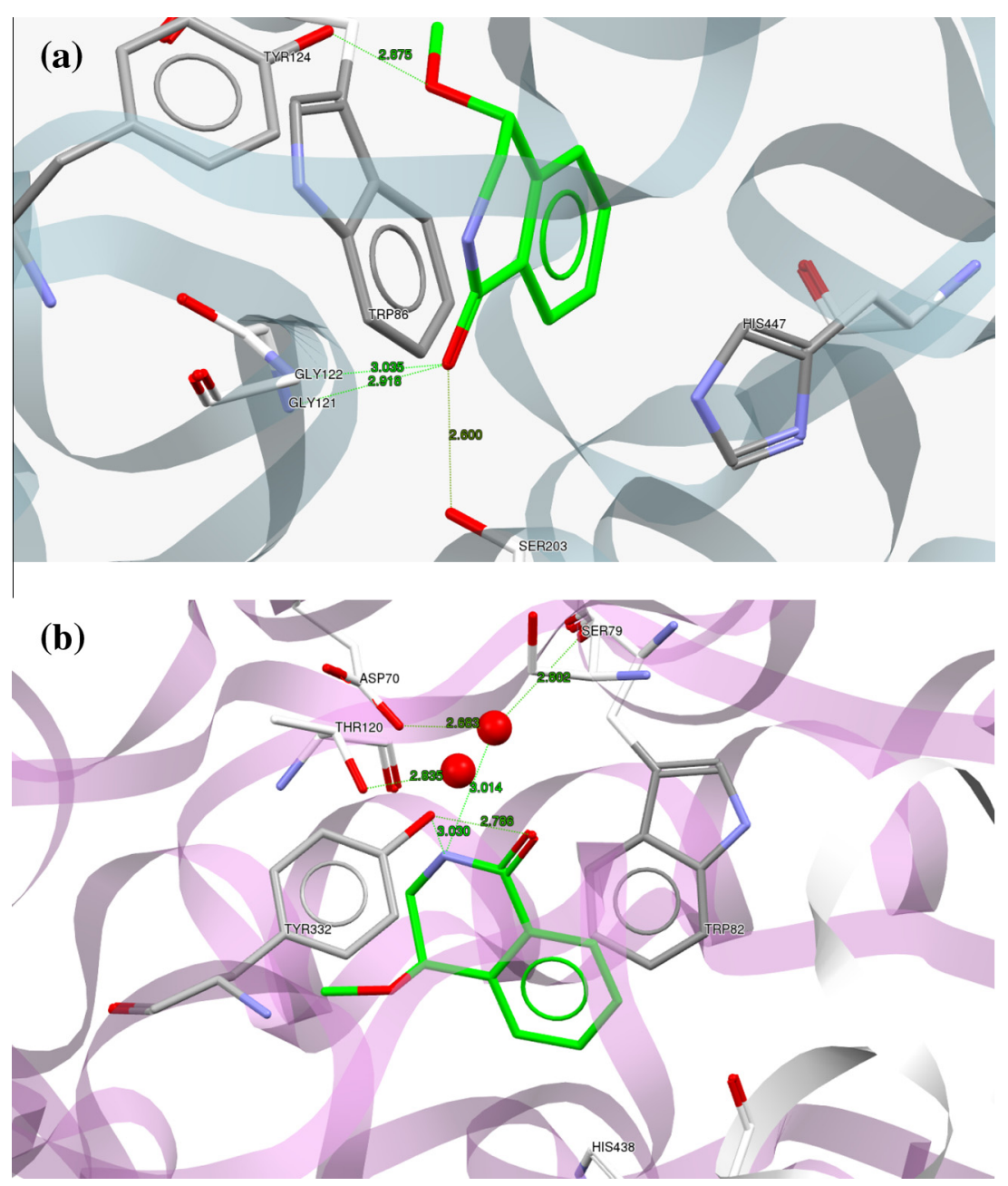

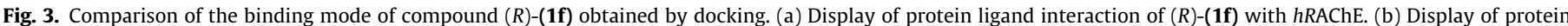

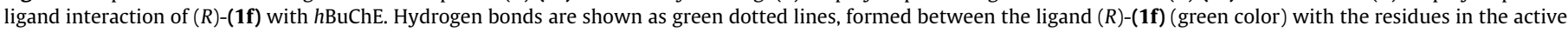
site (grey color). Water molecules in the active site are represented as red spheres. 
studies showed that the presence of sticky water molecules were beneficial only in the case of BuChE, perhaps because of its larger gorge.

Specifically, the first water molecule formed interactions with S79 $(2.80 \AA)$, D70 $(2.68 \AA)$, and the $(R)-(\mathbf{1 f})$ aromatic N $(3.01 \AA)$, whereas, the second water molecule formed an interaction with T120 (2.84 $\AA$ ). In addition, the hydroxyl group O3 of Y332 formed two H-bonds with the $\mathrm{N}$ of $(R)-(\mathbf{1 f})(3.03 \AA)$ and its carbonyl 02 $(2.79 \AA)$.

$(R)-(\mathbf{2 b})$ was also studied with $h \mathrm{BuChE}$ as it afforded the best inhibition values (Table 1$)$. The predicted binding mode of $(R)$ (2b) with $h$ BuChE (Fig. 4 b) indicated a strong stabilization of the complex around the PAS-site, which can be attributed to hydrogen bond networks. The bridging of the two water molecules in the active site includes $\mathrm{H}$-bonds of the first water molecule with the carbonyl 02 of $(R)-(\mathbf{2 b})(1.86 \AA)$, the hydroxyl of S79 $(2.80 \AA)$, and the carbonyl of D70 (2.68 $\AA$ ) respectively, whereas, the second water molecule formed a H-bond with the 03 of T120 (2.84 Å). Furthermore, the $(R)-(\mathbf{2 b})$ nitrogen formed a strong $\mathrm{H}$-bond with $\mathrm{O} 2$ of Y332 (2.95 $\AA$ ), whilst the $(R)-(\mathbf{2 b})$ hydroxyl group $\mathrm{O} 3$ formed a $\mathrm{H}$ bond with the aromatic N of W82 (3.03 $\AA$ ). Compound (2d) presented almost the same inhibition for $E q B u C h E$ as (2b). Interestingly, when the methyl group in $(R)-(\mathbf{2 b})$ was substituted with a methoxyl group in $(R)-(\mathbf{2 d})$ as shown in Fig. $S_{5}$ (supplementary information), there was a shift in the interaction of the amide $\mathrm{N}$ to form a H-bond with Y440 (2.79 $\AA$ ), instead of with Y332. Also there were other significant interactions, like: a $\pi-\pi$ stacking interaction with W82, a H-bond between the 4-OH oxygen and the Y440 residue, along with a tight $\mathrm{H}$-bond network formed between the carbonyl oxygen $(1.98 \AA), A 70$ (2.68 $)$ and S79 (2.8 $)$ and a water molecule.

Overall, a significantly weaker interaction was found in the $(R)$ (2b)-RhAChE complex (Fig. 4a), there was a $\pi$ - $\pi$ stacking interaction with W86 and two H-bonding interactions with E202 (2.797 $\AA$ ) and S203 (2.65 ̊), and this would explain its lower binding for EeAChE as compared to EqBuChE.

To finalize this section the following point should be noted; differences in results between the computational docking study and the experimental inhibition bioassays were inevitable, because (1) RhAChE and $h \mathrm{BuChE}$ crystal structures were used as input structures in the computational study whereas, eeAChE and eqBuChE were used in the bioassay and (2) only the $(R)$ enantiomers of the hit compounds were docked, whereas the racemic mixtures was screened in the bioassays.

\section{Saturation Transfer Difference - Nuclear Magnetic Resonance (STD - NMR)}

To validate the docking studies, we performed key STD-NMR experiments to map the ligand-protein interactions of compound
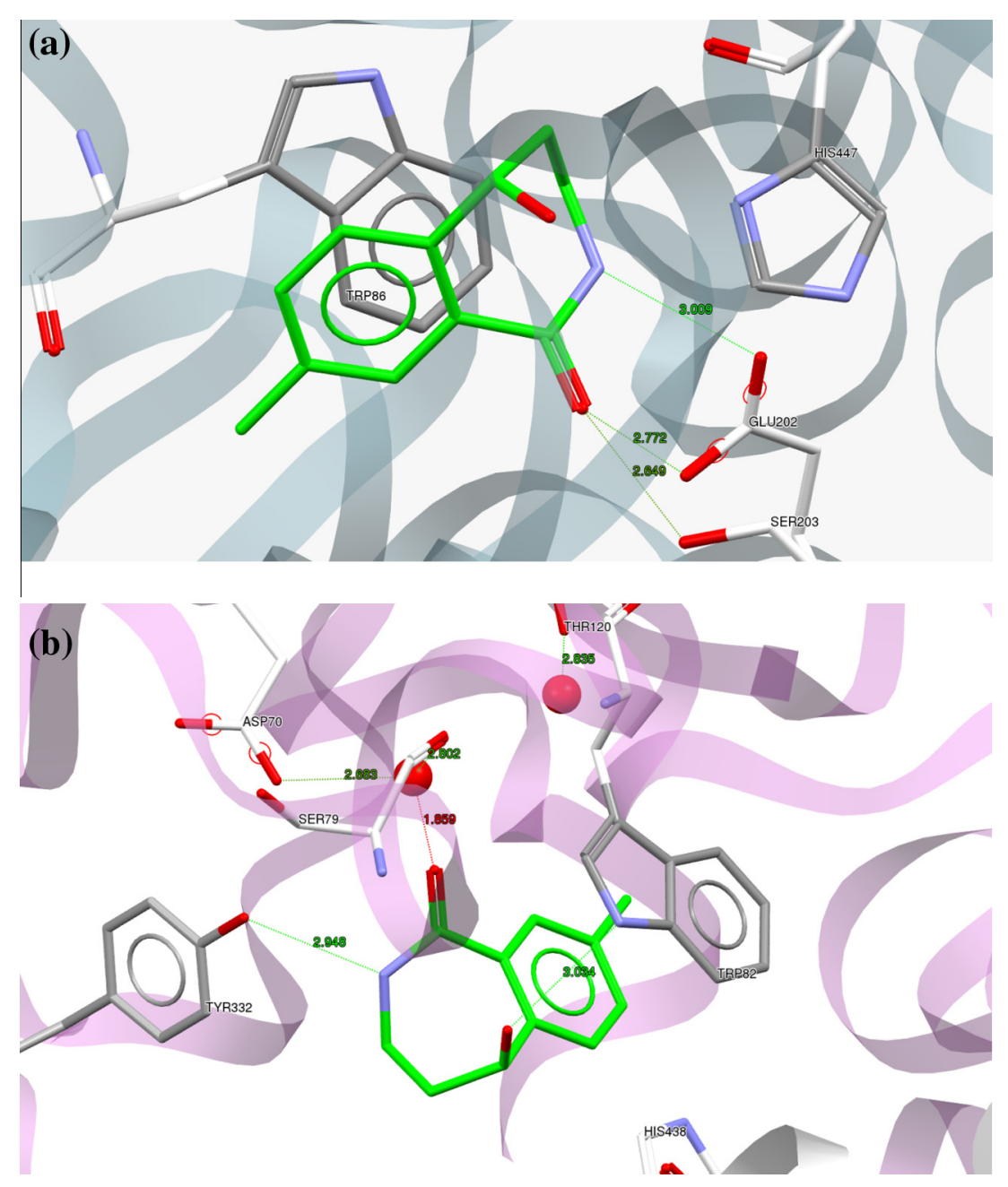

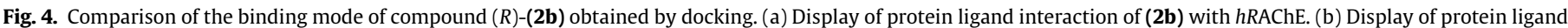

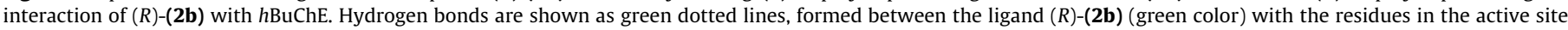
(grey color). Water molecules in the active site are represented as red spheres. 


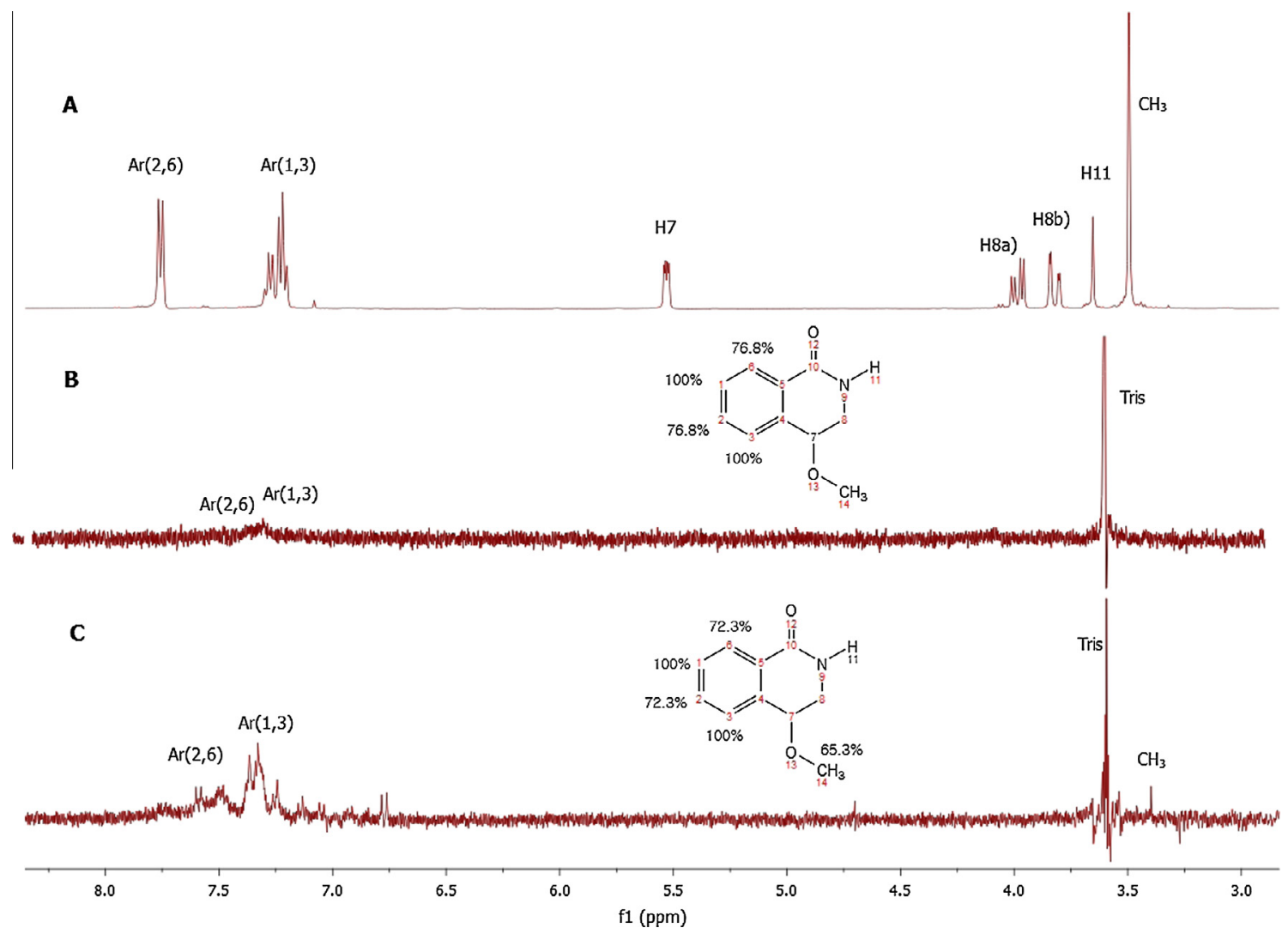

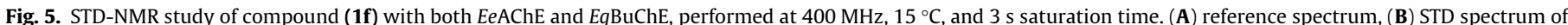

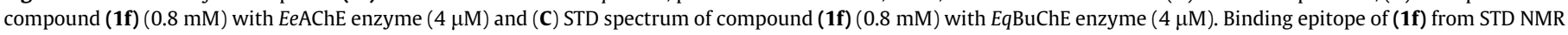

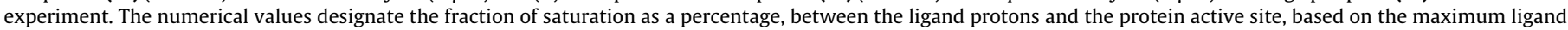
STD signal (H1,3 of $\mathrm{Ar} ; 100 \%)$.

rac-(1f) (Fig. 5) with both EeAChE and EqBuChE. The reference inhibitor used for these STD studies was galantamine (Fig. $\mathrm{S}_{6}$ ). To precisely map ligand epitopes in close contact with the protein, we acquired STD build up curves by collecting spectra at different saturation times [33-36]. The observed STD amplification ( A STD $_{\text {) is not }}$ the same for all the hydrogen molecules in compound (1f) (Fig. 6), as well as for galantamine (Fig. $\mathrm{S}_{7 \mathrm{c}}$ ). This is due to the fact that not all the proton signals in the STD-NMR spectrum received the same amount of saturation [33,34]. Thus, the distribution of saturation transferred among the different compound protons indicates spatial proximities between the protons of the compound molecule and the enzyme in the bound state [37]. Qualitatively, it can be assumed that a stronger intensity of a compound signal in the

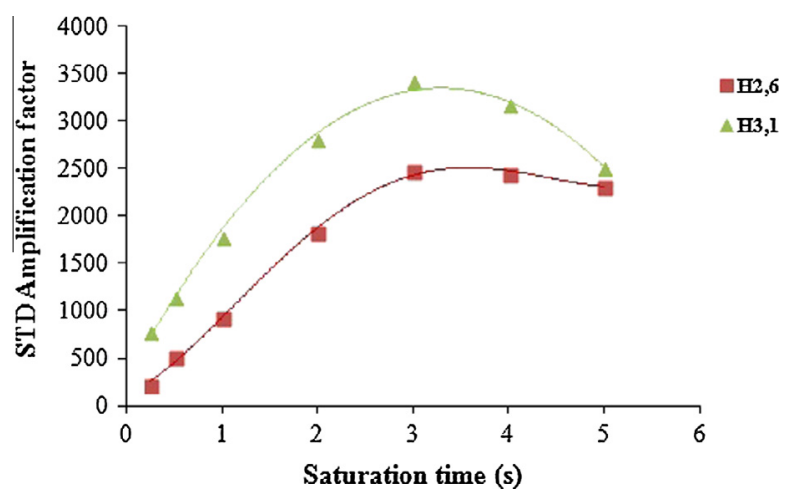

Fig. 6. STD amplification factor as a function of saturation time for a 200 -fold (1f) excess of EeAChE.
STD-NMR spectrum indicates closer inter-hydrogen distances between the compound proton and the receptor surface in the bound state [34]. To quantitatively express the relative STD effects at a given saturation time, all of the STD signals are normalized against the most intense signal, which is arbitrarily assumed to be $100 \%$ [37]. It can be concluded that protons with relative STD values close to $100 \%$ belong to parts of the compound that are very intimately recognized by the receptor binding-pocket, and hence must be regarded as important for the interaction.

Galantamine was chosen as it is a selective AChE inhibitor containing an azepanone unit, and is known to form a tight complex with TcAChE [38-40]. In the galantamine-TcAChE case, the amino acids residues that are within close proximity (i.e. defined as less than 5 A) were E199, F330, W84, H440, F288, F290, Y121, F331, G119, S200, G118, and G117 [38-40]. It binds principally with W84 (but not via the amine nitrogen $\mathrm{N}-10$ [40]) in the anionic binding site and F288 and F290 of the peripheral anionic site (PAS) at the entrance to the gorge. The crystal structure of galantamine-RhAChE was also determined and the binding was deemed to be similar to that of galantamine-TcAChE [40]. However, an additional hydrogen bond was formed between the galantamine $\mathrm{N}-10$ and Y337, which was in a different orientation than the corresponding $\mathrm{F} 330$ of TcAChE [41].

We conducted an STD-NMR study of the complex formed between EeAChE (commercially available and cheap) and galantamine (Fig. $\mathrm{S}_{4}$ and $\mathrm{S}_{5}$ ). It showed important interactions between the aromatic ring protons (H6, 100\% and $\mathrm{H} 568 \%$ ) and the enzyme, with the stronger interaction coming from H6. On comparing this with the report by Greenblatt et al. [38], this was presumably a $\pi-\pi$ interaction with most likely F295 or F297 of our enzyme (in 
the report by Greenblatt et al. [38] a proximity of these protons with the F331 residue was observed). The methoxyl group and the methyl group attached to N10 also showed significant interaction (62\% and $51 \%$, respectively). In the case of the methoxyl group this was probably due to H-bonding with $\mathrm{H} 447$ (in the study by Greenblatt et al. [38] there was a close approximation of $\mathrm{H} 440$ with the $\mathrm{MeO}$ group). The $\mathrm{OH}$ group also showed a significant interaction with the enzyme, registering an STD value of 53\%, and analogous to the X-ray crystal information [38] probably due to a $\mathrm{H}$ bond interaction with G121 or G122 (in the literature report there was a good approximation between the $\mathrm{OH}$ and G117). The significant values of $37 \%$ and $30 \%$ observed for $\mathrm{H}-15$ and $\mathrm{H}-9$, could probably be due to a $\pi-\pi$ and $\mathrm{CH} / \pi$ interaction [42] with W86. As in the $\mathrm{X}$-ray crystal structure the W84 indole was observed very close to this region of the molecule (Fig. $S_{6}$ and $S_{7}$ ).

In the case of compound (1) $)$, it was inferred that the hydrogen atoms namely, $\mathrm{H} 1$ and $\mathrm{H} 3$ were directly involved in the binding to the AChE and BuChE active sites (Fig. $5 \mathrm{~B}$ and $\mathrm{C}$ ). According to this qualitative analysis, the aromatic hydrogens (Fig. 5B and C) and the hydrogens from the methoxyl group (Fig. 5C), were observed to be strongly involved in the binding. In contrast, the hydrogens H7, H8a, H8b and H11 showed a relatively lower STD value, indicating that they were probably more distant from the active site residues for both enzymes [39]. Unfortunately as we could not localize the $\mathrm{NH}$ peak in the ${ }^{1} \mathrm{H}$ NMR spectrum we could not confirm if there was an interaction of the $\mathrm{NH}$ proton with the enzyme. These results are in agreement with the molecular docking prediction, even though in the case of the docking study a single enantiomer was used and in the STD-NMR rac-(1f) used. Inorder to support this hypothesis, much effort was made at accessing appropriate N-alkylated derivatives [24b], but due to purification issues it was not possible to isolate these derivatives in pure form.

\section{Conclusions}

From a series of bioassay studies on EeAChE and EqBuChE inhibition, compounds (1f) and (2a) were identified as two hit compounds that can be modified to furnish a series of lead compounds. Molecular docking showed that the amide $\mathrm{N}-\mathrm{H}$ group, the 4-methoxyl group and the azepanone core show good binding characteristics with both enzyme active sites. Compounds (2b) and (2d) showed the best $\mathrm{IC}_{50}$ values for $E q B u C h E$, indicating their potential as BuChE inhibitors. Compound (1f) showed Hbonding with the oxyanion pocket suggesting that it could inhibit AChE in a novel manner and a $\pi-\pi$ stacking interaction between its aromatic ring and the W86 residue in the anionic binding site, can give favorable stabilizing interactions in the ligand-protein complex. These assumptions have been validated by STD-NMR (unfortunately it could not confirm the $\mathrm{N}-\mathrm{H}$ interactions in (1f) and (2a)), which showed a strong interaction between the aromatic ring and the AChE active site.

Overall the compounds studied are weak ChEIs, but nonetheless, important insights have been obtained on their mode of inhibition so that more potent analogues can be designed, prepared and tested.

\section{Acknowledgment}

The authors gratefully acknowledge the following funding sources: the INMOLFARM - Molecular Innovation and Drug Discovery (ALENT-57-2011-20) of the FEDER-INALENTEJO program ALENT-07-0224-FEDER-001743, and for grants to CM (post-doc), ASJ (post-doc), DP (PhD), PB, and AG. The Foundation for Science and Technology (FCT) in Portugal for funding through the strategic project PEst-OE/QUI/UI0619/2014 and the FEDER-INALENTEJO program (ALENT-07-0262-FEDER-001878).

\section{Appendix A. Supplementary material}

It includes experimental procedures and compound characterization, STD NMR analysis and supplementary figures. Supplementary data associated with this article can be found, in the online version, at http://dx.doi.org/10.1016/j.bioorg.2016.05.004.

\section{References}

[1] M. Burke, Chem. World (August) (2014) 8: R.J. Hargreaves, ACS Med. Chem. Lett. 3 (2012) 862.

[2] D. Price, Annu. Rev. Neurosci. 9 (1986) 489.

[3] P. Kasa, Z. Rakonczay, K. Gulya, Prog. Neurobiol. 52 (1997) 511.

[4] P. Davies, A.J. Maloney, Lancet 2 (1976) 1403.

[5] M. Garcia-Ayllon, D. Small, J. Avilla, J. Sáez-Valero, Front. Mol. Neurosci. 4 (2011) 1.

[6] K. Ingkaninan, P. Temkitthawon, K. Chuenchom, T. Yuyaem, W. Thongnoi, J. Ethnopharmacol. (2003) 261.

[7] K. Ingkaninan, C. de Best, H. Irth, R. van der Heijden, A. Hofte, B. Karabatak, U. Tjaden, J. van der Greef, R. Verpoorte, J. Chromatogr. A (2000) 61.

[8] A. Cokugras, Turkish J. Biochem. 28 (2003) 54.

[9] G. Carmona, Drug Metab. Dispos. 28 (1999) 367.

[10] T. Zhao, K. Ding, L. Zhang, X. Cheng, C. Wang, Z. Wang, J. Chem. (2013) 1.

[11] D. Kuhl, R. Koeppe, S. Snyder, S. Minoshima, K. Frey, M. Kilbourn, Ann. Neurol. 59 (2006) 13.

[12] R. Van Marum, Fund. Clin. Pharmacol. 22 (2008) 265.

[13] A. San Juan, P. Bacalhau, C.S. Marques, D. Peixoto, A. Goth, M.R. Martins, A.T. Caldeira, A. Burke, unpublished results.

[14] M. Shamma, J.L. Moniot, J. Pharm. Sci. 61 (1972) 295.

[15] M. Shamma, J.L. Moniot, Isoquinoline Alkaloids Research, Plenum Press, New York, 1978.

[16] V.A. Glushkov, Y.V. Shklyaev, Chem. Heterocycl. Compd. 37 (2001) 663.

[17] B.D. Krane, M. Shamma, J. Nat. Prod. 45 (1982) 377.

[18] S. Gabriel, J. Colman, Ber. Deut. Chem. Ges. 33 (1900) 980.

[19] T.S. Sulkovski, M.A. Wille, Chem. Abstr. (1969) 71.

[20] D.N. Travers, M.A. Shammat, K. Shah, J. Pharm. Pharmacol. 30 (Suppl.) (1978) 20 P.

[21] O. Senda, O. Ohtani, E. Katho, H. Miyake, K. Fujiwara, Chem. Abstr. 95 (1981) 132692.

[22] M.S. Hasegava, K. Matsumoto, Y. Suzuki, I. Takahasi, Chem. Abstr. 121 (1994) 912.

[23] G. Ellman, K. Courtney, V. Andres, R. Featherstone, Biochem. Pharmacol. 7 (1961) 88.

[24] (a) C.S. Marques, D. Peixoto, A.J. Burke, RSC Adv. 5 (2015) 20108; (b) D. Peixoto, PhD Dissertation, University of Evora, 2015.

[25] P. Bacalhau, A. San Juan, C.S. Marques, D. Peixoto, A.J. Burke, A.T. Caldeira, M.R. Martins, Neurodegener Dis. 15 (Suppl. 1) (2015) 741.

[26] H. Gohlke, G. Klebe, Angew. Chem., Int. Ed. Engl. 41 (2002) 2644.

[27] D. Kitchen, H. Decornez, J. Furr, J. Bajorath, Nat. Rev. Drug Discov. 3 (2004) 935

[28] (a) X. Cousin, T. Hotelier, P. Liévin, J.P. Toutant, A. Chatonnet, Nucl. Acids Res. 24 (1996) 132;

(b) H. Dvir, I. Silman, M. Harel, T.L. Rosenberry, J.L. Sussman, Chemico-Biol. Int. 187 (2010) 10.

[29] S. Simon, J. Massoulié, JBC 272 (1997) 33045.

[30] (a) J.L. Sussman, F. Harel, C. Frolow, C. Ofner, A. Goldman, L. Toker, L. Silman, Science 253 (1991) 872;

(b) P. Bar-On, C.B. Millard, M. Harel, H. Dvil, A. Enz, J.L. Sussman, I. Silman, Biochemistry 41 (2002) 3555;

(c) J.L. Sussman, I. Harel, I. Silman, Chem. Biol. Inter. 87 (1993) 187.

[31] (a) B. Brus, U. Košak, S. Turk, A. Pišlar, N. Coquelle, J. Kos, J. Stojan, J.-P. Colletier S. Gobec, J. Med. Chem. 57 (2014) 8167;

(b) Y. Nicolet, O. Lockridge, P. Masson, J.C. Fontecilla-Camps, F. Nachon, J. Biol. Chem. 278 (2003) 41141;

(c) F. Nachon, O.A. Asojo, E.O. Borgstahl, P. Masson, O. Lockridge, Biochemistry 44 (2005) 1154.

[32] A. San Juan, A.J. Burke, in: EFMC International Symposium on Medicinal Chemistry, Lisbon, Portugal, September 7-11, 2014, Poster O002, 2014.

[33] A. Viegas, J. Manso, F. Nóbrega, E. Cabrita, J. Chem. Educ. 88 (2011) 990.

[34] J. Angulo, P.M. Nieto, Eur. Biophys. J. 40 (2011) 1357.

[35] B. Meyer, T. Peters, Angew. Chem. Int. Ed. 42 (2003) 864.

[36] A. Daranas, S. Khatib, R. Lysek, P. Vogel, J. Gavin, Chem. Open. 1 (2012) 13.

[37] M. Mayer, B. Meyer, Angew. Chem. Int. Ed. 38 (1999) 1784.

[38] H.M. Greenblatt, G. Kryger, T. Lewis, I. Silman, J.L. Sussman, FEBS Lett. 463 (1999) 321.

[39] H.M. Greenblatt, C. Guillou, D. Guenard, A. Argaman, S. Botti, B. Badet, C. Thal, I. Silman, J.L. Sussman, J. Am. Chem. Soc. 126 (2004) 15405.

[40] C. Bartolucci, E. Perola, C. Pilger, G. Fels, D. Lamba, Proteins 42 (2001) 182.

[41] J. Cheung, M. Rudolph, F. Burshteyn, M. Cassidy, E. Gary, J. Love, M. Franklin, J. Height, J. Med. Chem. 55 (2012) 10282.

[42] M. Nishio, M. Hirota, Y. Umezawa, The CH/P Interaction: Evidence, Nature and Consequences, Wiley -VCH, New York, 1998. 